\title{
DESAFIOS, POSSIBILIDADES E PERSPECTIVAS DA INSERÇÃO DAS LUTAS NO PLANEJAMENTO DE EDUCAÇÃO FÍSICA
}

\author{
Fernando Ferreira da Silva ${ }^{1}$
}

\section{RESUMO}

Ensinar luta nos espaços escolares possui o objetivo de informar aos educandos como controlar a mente para não usar a violência, ou seja, que estes percebam que tal prática deve servir para lazer e autodefesa; caso contrário, poderão colocar-se em risco. Assim, o presente artigo tem o intuito de compreender como as lutas podem se materializar de forma mais efetiva nas aulas de Educação Física na rede escolar do município de Armação dos Búzios no Rio de Janeiro/BR. O problema que fomentou essa investigação partiu da percepção, em momentos não monitorados de que, embora as lutas façam parte das diretrizes curriculares propostas para o ensino de Educação Física ao longo da Educação Básica, não se apresentam de forma efetiva nas aulas dessa disciplina, sendo substituídas por modalidades, como por exemplo, futebol, basquete e vôlei. Espera-se dar mais visibilidade às lutas, considerando-as ferramentas essenciais para a formação dos educandos.

Palavras-chave: Lutas; Educação Física; Diretriz Curricular.

\section{ABSTRACT}

Teaching struggle in school spaces aims to inform students how to control the mind so as not to use violence, that is, that they realize that such a practice should serve for leisure and selfdefense; otherwise, you may put yourself at risk. Thus, this article aims to understand how struggles can materialize more effectively in physical education classes in the school network of the municipality of Armação dos Búzios in Rio de Janeiro/BR. The problem that fostered this investigation started from the perception, at unmonitored moments that, although the struggles made part of the curricular guidelines proposed for the teaching of Physical Education throughout Basic Education, do not present themselves effectively in the classes of this discipline, being replaced by modalities, such as soccer, basketball and volleyball. It is expected to give more visibility to the struggles, considering them essential tools for the training of students.

Keywords: Fights; Physical Education; Curriculum Guideline.

\section{RESUMEN}

La enseñanza de las luchas en los espacios escolares tiene el objetivo de informar a los estudiantes cómo controlar la mente para no utilizar la violencia, es decir, que se den cuenta de que tal práctica debe servir para el ocio y la autodefensa; de lo contrario, pueden ponerse en riesgo. Por lo tanto, este artículo tiene como objetivo entender cómo las luchas pueden materializarse más eficazmente en las clases de educación física en la red escolar del municipio de Armação dos Búzios en Río de Janeiro/BR. El problema que impulsó esta investigación partió de la percepción, en momentos no monitorizados que, aunque las peleas forman parte de los lineamientos curriculares propuestos para la enseñanza de la Educación Física en toda la

\footnotetext{
${ }^{1}$ Mestrando em Ciências da Educação pela Universidad Interamericana - PY. Graduado no curso de licenciatura plena em educação física (técnico em desportos), pela Universidade Salgado de Oliveira - UNIVERSO em 2003, Pós-Graduado no curso de Pós-graduação Lato sensu em nível de Especialização em educação física escolar na área de ciências da saúde pela Faculdade da Região dos Lagos - FERLAGOS - 2005. E-mail: fernandocabofrio@gmail.com
} 
Educación Básica, no se presentan eficazmente en las clases de esta disciplina, siendo reemplazados por modalidades como futbol, baloncesto y voleibol. Se espera dar más visibilidad a las luchas, considerándolas herramientas esenciales para la formación de los estudiantes.

Palabras Clave: Peleas; Educación Física; Guía Curricular.

\section{INTRODUÇÃO}

Alvo de muito preconceito, as lutas, sejam elas artes marciais ou esportes de combate, sempre estiveram presentes na vida dos humanos. Sua trajetória evolutiva foi marcada por situações que colocaram os homens e as mulheres em situações nas quais tiveram de se posicionar de modo combativo para garantir a própria sobrevivência.

Pode-se ressaltar que, no passado, a batalha por alimentos, vestuário e ferramentas sempre foi cerceada por momentos de disputa entre indivíduos da mesma espécie ou entre os homens e os animais. Dessa forma, fica evidente que os humanos, naturalmente, possuem internalizado em suas ações a prática das lutas.

De acordo com estes fatos, hodiernamente, ainda é comum ouvir relatos de membros da comunidade escolar ou não, acerca do estímulo à violência ao se praticar artes marciais ou esportes de combate, principalmente entre os jovens. Importante reiterar que, as lutas estão presentes desde sempre na evolução humana, cabendo à atual geração promover a conscientização acerca da sua prática e não coibir tal aprendizado que é vital ao equilíbrio do corpo e da mente quando devidamente utilizado.

A partir desta premissa, as lutas passarão a ter um caráter mais disciplinador e modalizador da conduta dos discentes, já que atua no reforço dos valores éticos e morais voltados ao adequado uso das relações sociais. Outro ponto importante é que as lutas compõem as grades curriculares que orientam o ensino da Educação Física nas escolas de Educação Básica. O que parece ocorrer é uma seleção, sem atentar aos princípios didáticos, para determinados eixos presentes nas orientações disponibilizadas aos docentes. Há uma preferência por atividades que envolvam bola, por exemplo, e o uso demasiado das quadras, quando as escolas possuem.

Há aspectos periféricos que também dificultam o trabalho realizado com alunos nas aulas de Educação Física, visto que para colocar atividades 
esportivas em prática, a escola precisa contar com recursos materiais específicos a fim de garantir a segurança dos infantes. A ausência do uniforme adequado, por exemplo, costuma ser um dos aspectos dificultosos na execução das práticas esportivas no espaço escolar. No caso do componente luta, isso fica mais evidente porque existem artes marciais e esportes de combate que precisam do uniforme para se efetivarem.

Em relação ao judô, deve-se utilizar o uniforme denominado kimono na cor azul ou branca, sendo chamado de judogi, a contração de "judo + dogi", o que traduzindo livremente seria algo como "uniforme utilizado para a prática do caminho suave". As cores variam e existe ainda uma diferença entre o judogi e judogui. Segundo a tradição, o judogi é o quimono branco tradicional utilizado para apresentações e o judogui é o kimono de luta utilizado para os treinos de judô.

Existe também o jiu jitsu que utiliza o kimono, diferindo-se do judô quanto à atribuição das cores. Esse vestuário facilita a 'comunicação para fora' e é responsável, inclusive, pela identificação da equipe. No caso das competições oficiais, a Confederação Brasileira de Jiu Jitsu permite que apenas sejam usados kimonos brancos, azuis e pretos durante eventos oficiais. Já em treinos, não há restrições e o praticante pode ficar à vontade para usar modelos camuflados ou com outras cores que desejar. Neste caso, o mais indicado é comprar um kimono personalizado e outro voltado para competições.

Por último, tem-se o caratê que é a tradicional arte marcial possuindo o kimono, ou Karate-Gi, exclusivamente na cor branca. Nenhuma outra cor ou detalhe é permitido. Um dos motivos para a exigência do kimono branco para a prática do caratê é o simbolismo que a cor branca traz. Ela representa pureza, que no caratê se aplica ao fato de não serem utilizados quaisquer tipos de armas, apenas a técnica pura e a força do homem.

Estes aspectos foram pontuados para ratificar a necessidade de disponibilizar vários uniformes e isso demanda alto investimento, uma vez que a utilização deve ser individual. Dessa forma, além do profissional de educação física precisar reconhecer a relevância das lutas no espaço escolar, a equipe diretiva e o poder público devem gerir e destinar recursos que atendam às reais necessidades das crianças e jovens na realização destas aulas. 


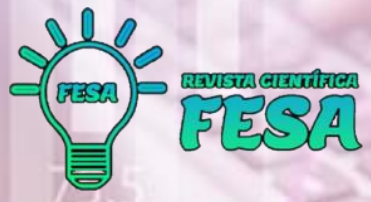

Desse modo, a presente pesquisa parte de um problema gerador de toda a investigação: percepção, em momentos não monitorados, de que, embora as lutas façam parte das diretrizes propostas para o ensino de Educação Física ao longo da Educação Básica, não se apresentam de forma efetiva nas aulas dessa disciplina, sendo substituídas por modalidades, como por exemplo, futebol, basquete e vôlei. Assim, esse artigo divide-se em Currículo de Educação Física para a Educação Básica; Lutas como Elemento Formador; Papel do Professor na Inclusão das lutas nas aulas de Educação Física; e Metodologia, sendo acrescidas as considerações finais e as referências.

\section{CURRÍCULO DE EDUCAÇÃo FÍSICA PARA A EDUCAÇÃO BÁSICA}

A educação, com o passar do tempo, buscou caminhos para uniformizar a oferta de conteúdos ao longo da Educação Básica em relação às aulas de Educação Física a fim de disponibilizar oportunidades equânimes para todos os estudantes. Dessa forma, há orientações de amplitude nacional e outros que atendem mais às demandas locais, como os documentos elaborados e disponibilizados aos estudantes das redes estaduais e municipais. Com o objetivo de proporcionar o acesso à cultura corporal do movimento e/ou às práticas corporais, a Educação Física foi inserida enquanto componente curricular nas escolas regulares brasileiras (BRASIL, 1998).

Entende-se que existem parâmetros curriculares normativos da Educação Básica que embasam o planejamento curricular das escolas. Originadas na Lei de Diretrizes e Bases da Educação (BRASIL, 1966), e fixadas pelo Conselho Nacional de Educação (CNE), elas direcionam as atividades para a Educação Infantil e Ensinos Fundamental e Médio.

Assim, o objetivo das orientações curriculares é assegurar a autonomia da escola e da proposta pedagógica. Assim, as instituições são estimuladas a montarem seus currículos a partir das áreas de conhecimento e dos conteúdos que acham mais adequados. A ideia é assegurar que as disciplinas sejam trabalhadas a partir de alguns parâmetros específicos, como o tipo de pessoas atendidas, a região em que está inserida e outros aspectos relevantes para a formação física, mental e social dos discentes. Sobre tal conteúdo, justifica-se a importância de sua inserção nas escolas de modo que, além de dar acesso a

Tendências Multidisciplinares: Investigação, Método e Ciência 
esta prática corporal, a mesma pode ser um elemento canalizador da violência, podendo melhorar o repertório motor a partir de novos movimentos (BREDA et al., 2010; GOMES, 2008; RUFINO; DARIDO, 2015)

De acordo com esse contexto, a disciplina de Educação Física possui eixos norteadores com elementos específicos para serem trabalhados nas aulas. Os conteúdos em si dividem-se em blocos como conhecimentos sobre o corpo, esportes, jogos, lutas, ginásticas; e atividades rítmicas e expressivas denominadas práticas da cultura corporal porque possuem presença marcante na sociedade brasileira, cuja aprendizagem favorece a ampliação das capacidades de interação sociocultural, o usufruto das possibilidades de lazer, a promoção e a manutenção da saúde pessoal e coletiva (BRASIL, 1996).

Os conteúdos são um recorte possível da enorme gama de conhecimentos que vêm sendo produzidos sobre a cultura corporal e estão incorporados pela Educação Física. Sobre as lutas em específico, os Parâmetros Curriculares Nacionais asseveram que:

\begin{abstract}
As lutas são disputas em que o(s) oponente(s) deve(m) ser subjugado(s), mediante técnicas e estratégias de desequilíbrio, contusão, imobilização ou exclusão de um determinado espaço na combinação de ações de ataque e defesa. Caracterizam-se por uma regulamentação específica, a fim de punir atitudes de violência e de deslealdade. Podem ser citados como exemplo de lutas desde as brincadeiras de cabo-de-guerra e braço-de-ferro até as práticas mais complexas da capoeira, do judô e do caratê (BRASIL, 1998).
\end{abstract}

Importante mencionar que as atividades esportivas são sempre divulgadas nos meios de comunicação e dentro da comunidade escolar e devem fazer parte do conteúdo ao longo da Educação Básica, se for abordado sob o enfoque da apreciação e da discussão de aspectos técnicos, táticos e estéticos, ou em contextos mais específicos (como torneios e campeonatos) que possibilitam que os alunos vivenciem uma situação mais caracterizada como esporte.

Em especial, para a Prefeitura de Armação dos Búzios - RJ, há um documento específico denominado Proposta Curricular para a disciplina de Educação Física que traz, em seu corpus, as Unidades Temáticas, os Objetos de Conhecimento e as Habilidades que se pretende aprimorar.

Como Unidades Temáticas, o documento elenca Brincadeiras e jogos; Esportes; Ginásticas; Danças; Lutas; e Práticas corporais de aventura. Já os 
Objetos de Conhecimento se relacionam direta e respectivamente às Unidades temáticas, sendo denominados: Jogos eletrônicos, Jogos da cultura popular e Jogos adaptados; Esportes de marca, Esportes de precisão, Esportes de invasão, Esportes técnico-combinatórios, Esportes Adaptados, Esportes de rede/parede, Esportes de campo e taco, Esportes de combate, Esportes de areia, Primeiros socorros; Ginástica de condicionamento físico, Ginástica de conscientização corporal; Danças urbanas, Danças de salão, Danças Regionais; Lutas do Brasil, Lutas do mundo; Práticas corporais de aventura urbanas e Práticas corporais de aventura na natureza.

Embora o documento não traga uma diferenciação entre os conceitos de competência e habilidades, lista, de modo organizado, todas as habilidades que devem ser aprimoradas em relação à Unidade Temática Lutas. A fim de melhor organizar tais conteúdos, essas metas estão organizadas no quadro a seguir:

Quadro 1. Habilidades para a unidade temática Lutas na Proposta Curricular de Armação dos Búzios

\section{6 e 7ํano - Educação Física}

Experimentar e fruir a execução dos movimentos pertencentes às lutas do mundo, adotando procedimentos de segurança e respeitando o oponente.

Planejar e utilizar estratégias básicas das lutas experimentadas, reconhecendo as suas características técnico-táticas.

Discutir as transformações históricas, o processo de esportivização e a midiatização de uma ou mais lutas, valorizando e respeitando as culturas de origem.

Discutir sobre as possibilidades das práticas corporais de lutas como elemento de ascensão socioeconômica.

\section{8ํ e 9ำ ano - Educação Física}

Experimentar e fruir diferentes práticas corporais de aventura na natureza, valorizando a própria segurança e integridade física, bem como as de outrem, respeitando o patrimônio natural e minimizando os impactos de degradação ambiental. 
Identificar riscos, formular estratégias e observar normas de segurança para superar os desafios na realização de práticas corporais de aventura na natureza.

Identificar as características (equipamentos de segurança, instrumentos, indumentária, organização) das práticas corporais de aventura na natureza, bem como suas transformações históricas.

Perceber as práticas corporais de aventura como elemento de exploração econômica e, portanto, ter em vista a necessidade da preservação do meio ambiente.

Fonte: Proposta Curricular de Armação dos Búzios.

Posto isso, importante destacar que as lutas, esportes de combate e as artes marciais são ricas em filosofia, entretanto não está previsto nos documentos e leis que a filosofia das lutas e artes marciais estejam presentes nas aulas de Educação Física. Além de desenvolver as capacidades físicas, as lutas auxiliam o sujeito na sua relação consigo mesmo e com o grupo, ao propiciar elementos que visam à socialização, a competitividade, a disciplina e 0 respeito, característicos de sua tradição e filosofia (PREYER, 2000, p.71).

Assim, a filosofia das artes marciais está presente quando se fala em respeitar o próximo, conhecer os limites e resguardar a saúde do colega durante as aulas. Refletir sobre suas ações pode, de maneira simples, fazer parte de um programa mais elaborado para esta valorosa experimentação e inserção dos alunos às lutas e às artes marciais.

\section{LUTAS COMO ELEMENTO FORMADOR}

As unidades escolares têm um papel de socialização do saber sistematizado (SAVIANI, 1992). Dessa forma, o universo escolar deve propiciar uma educação que precisa transpor a que é praticada nos núcleos familiares, fortalecendo assim, a convivência humana, oportunizando novos aprendizados e autonomia para realizações pessoais e profissionais dos seus integrantes.

As lutas, envolvendo esportes de combate e artes marciais, são práticas competitivas, populares e reconhecidas ferramentas na educação de crianças e jovens, e, mesmo possuindo diversos profissionais qualificados em centros de 
artes marciais e academias, a maioria das escolas no Brasil, não utilizam este conteúdo nas aulas. Realidade diferente dos países orientais que utilizam as artes marciais nas aulas de Educação Física (MOCARZEL, 2011).

Em âmbito nacional, os esportes de combate e as artes marciais são vistas como atividades que estimulam a violência dos alunos e que este seria o principal motivo para a falta de uso das artes marciais nas aulas de Educação Física Escolar (VERTONGHEN, 2010). Evidencia-se que essas práticas devem ser de conhecimento legítimo da Educação Física, mas o desconhecimento especializado nas técnicas e seus princípios se tornaram uma barreira para 0 uso da modalidade nas escolas (GOMES, 2008).

Ferreira (2006) afirma que, nos cursos de graduação em Educação Física, muitos consideram a disciplina que envolve os esportes de combate e as artes marciais como descartável. $\mathrm{O}$ autor ainda afirma a possibilidade de em apenas um semestre de aula o educando da graduação se tornar apto ao ensino dos esportes de combate e das artes marciais com contextos lúdicos objetivando a intensão concreta de atuar no ensino escolar.

Portanto, a ausência das lutas, nos conteúdos da Educação Física escolar, é resultado da massiva proeminência da formação esportista que, na ênfase teoria e prática voltada ao esporte, aos gestos técnicos, ainda pregam o saber fazer para ensinar (DARIDO 2003).

Darido (2003), em suas pesquisas, obteve resultados que demonstram a falta de interesse dos professores à modernização do conhecimento, à visão tecnicista e higienista onde a repetição pela repetição torna-se alienante, sem produção, sem crescimento, sem aprendizagem, perde-se então o sentido de se ter um professor frente aos alunos (TORRES, 2010).

\section{PAPEL DO PROFESSOR NA INCLUSÃO DAS LUTAS NAS AULAS DE EDUCAÇÃO FÍSICA}

Por mais bem elaboradas que as orientações curriculares sejam, a empiria dos conhecimentos cabe ao profissional de educação que atua diretamente com alunos em sala de aula. Esse ato prático, embora personalíssimo, não pode ser unicamente responsabilidade do docente, visto que este precisa de meios para efetivar um trabalho que gere resultados e aprimore efetivamente o ensino 
disponibilizado. No entanto, cabe ao profissional de educação física criar estratégias para amenizar os problemas que aos poucos poderão ser totalmente resolvidos.

Com base nessa perspectiva, é possível evidenciar as pesquisas de Rufino e Darido (2015) que mencionam a necessidade de adequar as propostas pedagógicas para o ensino das lutas a partir do ensino global, e não se focando em modalidades especificas. Para que este ensino seja possível durante as aulas de educação física, os autores propõem a utilização de materiais alternativos, como a substituição de tatames por colchonetes; sacos de pancada por bexigas; espadas de metal por jornal, dentre outros passíveis de adaptações mantendo a devida segurança dos partícipes.

Entende-se que por ser uma disciplina que possui um viés mais prático do que teórico, a disponibilização de materiais adequados e uma infraestrutura segura são essenciais para o trabalho docente.

\begin{abstract}
Independentemente das dificuldades que os professores tenham para ministrar as lutas dentro do conteúdo da Educação Física Escolar, estes poderão recorrer a diversos recursos como vídeos, palestras, atividades lúdicas, aulas de campo de modalidades diversificadas, conhecimento da história de cada modalidade, seus ídolos, regras, países onde são mais difundidas, visitas técnicas dentre outras. Importante enfatizar que o mais importante é a vontade de fazer algo diferente (MAZINI FILHO et al., 2014).
\end{abstract}

Sabe-se que em muitas escolas brasileiras, uma sala de esportes ou uma quadra adequada costumam ser a exceção quando deveriam ser a regra. A compra de tatames costuma ser dificultosa por conta de dois motivos recorrentes nos espaços escolares: alto custo de aquisição e local adequado para armazenar estes materiais. Muitas vezes, quando fazem parte do inventário da unidade, ficam empilhados em áreas comuns e carecem de higienização. Contudo, é imprescindível que haja um olhar diferenciado sobre os benefícios do esporte na escola e seja colocado em prática o que consta nos Parâmetros Curriculares Nacionais (1998).

O lazer e a disponibilidade de espaços para atividades lúdicas e esportivas são necessidades básicas e, por isso, direitos do cidadão. Os alunos podem compreender que os esportes e as demais atividades corporais não devem ser privilégio apenas dos esportistas ou das pessoas em condições de pagar por academias e clubes. Dar valor a 
essas atividades e reivindicar o acesso a elas para todos é um posicionamento que pode ser adotado a partir dos conhecimentos adquiridos nas aulas de Educação Física (BRASIL, 1998).

Atrelado a isso, o profissional da área de Educação Física deve ter claro o seu papel político na formação dos cidadãos plenos com valores sociais, frutos de suas experiências constituídas aos poucos e ao longo do processo de aprendizagem, cabendo a elaboração e adequação das aulas às situações que podem ser previstas durante a prática, dando especial atenção ao nível de conhecimento de cada aluno, definindo objetivos concretos e atingíveis (MATTOS, 2008, p. 59).

Ainda, percebe-se que a construção de valores positivos e negativos nos alunos depende da forma como o professor avalia o comportamento deles e os faz refletir criticamente os preceitos filosóficos das artes marciais (MOCARZEL, 2011). Os temas como preconceito, violência, gênero, esporte e saúde devem ser trabalhados através de debates nas aulas de lutas e artes marciais na Educação Física como instrumentos transformação sejam eles através do Karatê ou outra Luta (KUNZ, 2006).

Dessa forma, fica evidente que a Educação Física faz parte da Educação Básica em sua tarefa educacional, assim como os esportes de combate às artes marciais, sendo preciso entender e saber que tipo de ser humano se quer formar, adicionando reflexão e emoções às respostas do homem; e também às ações que não são físicas e nem psíquicas, mas obrigatórias à concretização dos planos políticos pedagógicos e ao desenvolvimento das técnicas, discursos, relações sociais e programas de ensino para a formação do homem total e unitário (SHIGUNOV, p. 333, 2000).

\section{METODOLOGIA}

Esta pesquisa é caracterizada por uma revisão bibliográfica de natureza qualitativa em trabalhos somente em português com as palavras-chave "Lutas"; "Educação Física"; e "Diretriz Curricular". A coleta de dados foi realizada com o uso de fontes de consultas, livros, artigos, teses, dissertações e como fonte principal, utilizou-se a base de periódicos da CAPES, além das bases do Scielo 
e Lilacs. Também foram revisados estudos de tese e livros disponíveis na internet e na biblioteca de universidades federais.

\section{CONSIDERAÇÕES FINAIS}

Observa-se neste estudo que, em todas as culturas primitivas da préhistória, houve o desenvolvimento de técnicas e estratégias de combate para fins de ataque e defesa do oponente nas diferentes formas de luta ou esporte de combate. Além disso, há de se defender o uso das diversas práticas de luta no contexto escolar devido as grandes contribuições que podem trazer se forem utilizadas de maneira adequada.

Espera-se, portanto, que, com este estudo bibliográfico, as lutas sejam incorporadas nas aulas de Educação Física ao longo da Educação Básica por parte dos docentes formados nessa área do conhecimento a fim de que esse componente se constitua como relevante para o estudante, buscando a construção de sua identidade, servindo de aprimoramento para a qualidade do ensino disponibilizado nas unidades escolares.

\section{REFERÊNCIAS BIBLIOGRÁFICAS}

ALMEIDA, A. C. P. C. de; SHIGUNOV, V. A atividade Lúdica Infantil e suas Possibilidades. Revista da Educação Física/UEM, Maringá, v. 11, n. 1, p. 6976, 2000.

BRASIL. Secretaria de Educação Fundamental. Parâmetros Curriculares Nacionais: Educação Física / Secretaria de Educação Fundamental. Brasília: MEC I SEF, $1998 . \quad$ Disponível em: http://portal.mec.gov.br/seb/arquivos/pdf/fisica.pdf. Acesso em 04 de jan. de 2021.

BRASIL. Senado Federal. Lei de Diretrizes e Bases da Educação Nacional: no 9394/96. Brasília: 1996.

BREDA, M.; GALATTI, L.; SCAGLIA, A. J.; PAES, R. R. Pedagogia do esporte aplicada às lutas. São Paulo, Phorte, 2010. 
DARIDO, S. C. Educação Física na escola: questões e reflexões. Rio de Janeiro: Guanabara Koogan, 2003.

FERREIRA, H. S. As lutas na Educação Física escolar. Rev. de Ed. Física, № 135, p.36-44, nov. 2006.

GOMES, M. S. P. Procedimentos pedagógicos para o ensino das lutas: contextos e possibilidades. Dissertação (Mestrado em Educação Física) Faculdade de Educação Física, Universidade Estadual De Campinas, Campinas. 119p. 2008.

KUNZ, E. Transformação didático-pedagógica do esporte. 7. ed. ljuí: Unijuí, 2006.

MATTOS, M. G. de. Educação Física infantil: construindo o movimento na escola. 7. Ed. São Paulo: Ágora, 220p. 2000.

MAZINI FILHO, M. L.; SIMÕES, M. R.; VENTURINI, G. R. O.; SAVÓIA, R. P.; MATTOS, D. G.; AIDAR, F. J.; COSTA, S. P. O ensino de lutas nas aulas de educação física escolar. Cinergis, Santa Cruz do Sul, v. 15, n. 4, p. 176-81, 2014.

MOCARZEL, R. C. da S. Artes marciais e jovens: violência ou valores educacionais? Um estudo de caso de um estilo de Kung-fu / Rafael Carvalho da Silva Mocarzel. - Niterói, 108p. 2011.

PREYER, C. T. Educação física escolar: a importância da diversificação no ensino de seus conteúdos. Campinas, 2000. Disponível em: www.bibliotecadigital.unicamp.br/document/?view=000330320. Acesso em: 05 de jan. de 2021.

RUFINO, L. G.; DARIDO, S. C. O ensino das lutas nas aulas de educação física: análise da prática pedagógica à luz de especialistas, 2015. Disponível em: https://www.scielo.br/pdf/refuem/v26n4/1983-3083-refuem-26-04-00505.pdf Acesso em: 02 de jan. de 2021.

SAVIANI, D. Sentido da pedagogia e o papel do pedagogo. Revista ANDE, São Paulo, no 9, p. 27-28, 1985.

SAVIANI, D. Pedagogia histórico-crítica: primeiras aproximações. São Paulo: Cortez, 1992. 
TORRES, L. R. Propostas pedagógicas para o ensino de lutas em escolas: uma visão sobre o universo do Kung Fu. Revista Digital. Buenos Aires, Ano 15, no 147, 2010.

VERTONGHEN, J. The social-psychological outcomes of martial arts practice among youth: A review. Journal of Sports Science and Medicine. n.9, p.528537, 2010. 